\title{
Review of Clinical Anesthesia
}

\author{
Neil Roy Connelly, David G. Silverman. Lippincott Williams and Wilkins, Philadelphia, \\ PA, 2009, 5th edition, 315 pp, ISBN 13:978-0-7817-8951-6, ISBN 10: 0-7817-8951-6
}

\author{
Udell Larsen, MD
}

Published online: 30 September 2009

(c) Canadian Anesthesiologists' Society 2009

Review of Clinical Anesthesia, 5th edition is in fact an extension of the comprehensive, well-regarded parent textbook, Clinical Anesthesia, 6th edition. Designed as a means of self-assessment, this review textbook that examines the speciality of anesthesia is divided into 60 separate topics, i.e., chapters that have all been revised or enhanced. The question and answer format of the text probes the reader's knowledge and helps the reader to identify any gaps in understanding.

While the editor's names may not be as familiar as those attached to the parent text, this in no way detracts from the final product. They were wise to include contributors from many sub-specialties of anesthesia as well as a number of residents. This multi-dimensional cast has gathered an extensive fund of knowledge that is substantiated by both the types of questions and the degree of difficulty that will surely challenge any reader. This well-organized, extensive review covers topics ranging from the History of Anesthesia to Office-Based Anesthesia and everything in between. The questions are relevant, carefully thought out, and up-todate, and each question has a corresponding comprehensive answer that includes a heading and page number directing the reader to a specific section in the parallel textbook, Clinical Anesthesia, 6th edition. This feature facilitates an extremely quick and concise reference when the reader needs further deliberation concerning the original question. This text provides an excellent review of the vast specialty of anesthesia while avoiding any esoteric information.

The book can be used predominantly as a means for residents to self-assess before undertaking a written examination. However, if properly utilized, this review textbook could be an excellent tool for anyone, from novice to expert, to identify the areas of anesthesia that need further focused study.

A shortcoming of the text for Canadian anesthesia residents preparing for their Royal College of Physicians and Surgeons of Canada examinations is the fact that the format of the written questions is not what they will experience in the final examination. In addition to the standard A-type questions, this review book utilizes K-type questions that the College no longer uses. Furthermore, for the past two years, a large portion of the College's written examination has consisted of short answer questions, which are not included in this review text.

Overall, this is an excellent well-organized comprehensive review text that could be equally at home on the bookshelves of trainees and faculty alike.
U. Larsen, MD ( $\square)$

University of Calgary, Calgary, Canada

e-mail: utrl@hotmail.com 